\title{
Doping: argumentos em discussão
}

Otávio Tavares ${ }^{1}$

\section{Resumo}

O doping constitui-se num grande problema do esporte contemporâneo. Apesar do discurso quase hegemônico de condenação desta prática, a eliminação doping do cenário esportivo parece ainda distante. Baseado na premissa de que argumentos são válidos na medida de sua correspondência na prática, o objetivo deste texto é examinar os argumentos que fundamentam o discurso sobre a imoralidade do doping em termos de seu mérito lógico. Procuramos demonstrar através de perguntas e comparações que estes argumentos são falhos na medida em que não podem ser validados na prática. Por fim procuramos situar a questão do doping dentro de uma dimensão simbólica do esporte.

Descritores: Doping; Atleta; Ética.

\begin{abstract}
The use of doping is one of the major issues of contemporary sport. The solution of the drug-taking problem seems to be distant despite the almost hegemonic opinion against doping. If arguments should correspond practical consequences, the aim of this paper is to exam the arguments against doping in sportin terms of their logic. We tried to demonstrate through questions and comparisons that those arguments are not valid since they do not correspond practical consequences. Finally we try to focus doping against the symbolic dimension ofsport.
\end{abstract}

Key Words: Doping; Ethics;Athlete.

\section{Introdução}

Não parece ser difícil constatar que embora seja, institucionalmente falando, quase hegemônico o discurso de condenação ao uso de substâncias dopantes, paradoxalmente, é cada vez mais certo que a eliminação do uso destas substâncias hoje proscritas para uso atlético parece cada vez mais distante de uma solução. Em face da observada persistência da problemática do doping mesmo diante de regulamentos, controles e campanhas, o objetivo deste texto é examinar os argumentos que fundamentam o discurso sobre a imoralidade e a ilegalidade do doping em termos de seu mérito lógico. Partindo da premissa clássica de Cícero de que argumentos são "as razões que dão fé a alguma coisa duvidosa", sua conseqüência lógica é que eles possam ser capazes de fazer passar a proposição da imoralidade do doping como uma coisa verdadeira. Afinal, como afirma Abbagnano (1998:79), um argumento é algo "que de algum modo produza um grau qualquer de persuasão". Para que isto se realize, claro está que esta capacidade de persuasão será tanto maior quanto mais coerente for sua correspondência com a prática. Assim, os argumentos anti-doping não serão examinados pelo caráter de sua veracidade (por que aceitamos que podem ser verdadeiros), mas sim pela qualidade de serem em si mesmos necessários e suficientes ao combate ao uso de drogas no esporte.

E evidente que sendo o esporte um fenômeno complexo não é possível pensar o problema do doping como uma questão de bons ou maus argumentos apenas. Na verdade, o exame da validade de um argumento, de sua correspondência a conseqüências práticas só é possível a partir do diálogo com o contexto sócio-histórico da produção da moral so-

\section{Movimente}


cial e com a perspectiva interna do praticante ${ }^{2}$. É a partir desta compreensão que tentamos abordar este problema complexo. Como não vivemos num mundo de anjos inocentes nem de robôs friamente racionais mas naquele no qual nossos sentimentos, desejos e pulsões são limitados pela noção moral de certo e errado, acredito que a qualidade dos argumentos colocados se constituem numa dimensão importante de análise.

Seja no oriente, seja no ocidente, em $\mid \begin{aligned} & \text { Gostaria de enfatizar } \\ & \text { porém que não se trata de }\end{aligned}$ sociedades simples ou defender aqui o uso do complexas, a doping ou mes-mo de sua utilização de algum legalização, mas de lançar artificio (físico, um olhar crítico sobre a químico, psicológico) $\begin{array}{r}\text { razoabilidade, a coerência } \\ \mathrm{e}\end{array}$ destinado a aumentar e a efetividade dos as capacidades fisicas argumentos anti-doping humanas parece de tal este texto não ambiciona forma presente que, propor uma solução para o penso, teríamos problema do doping mas poucas dificuldades e refletir a partir de questões em classifica-los Como e comparações sobre o um universal poder dos argumentos cultural. alguma coisa que parece duvidosa para muitos.

\section{Esporte, auto-controle e doping}

O uso de substâncias que aumentem o rendimento físico ou que pelo menos gerem a crença nisto é quase tão antiga quanto o desenvolvimento das atividades físicas organizadas. Seja no oriente, seja no ocidente, em sociedades simples ou complexas, a utilização de algum artifício (físico, químico, psicológico) destinado a aumentar as capacidades físicas humanas parece de tal forma presente que, penso, teríamos poucas dificuldades em classifica-los como um universal cultural. Entretanto, estas práticas, se observadas do ponto de vista tanto dos sentidos quanto das formas, atingem uma variabilidade bastante elevada $^{3}$.

As sociedades modernas, todavia, tem se transformado no sentido de uma maior 'docilização' das normas de conduta e relações em seus diversos tempos e espaços sociais, mormente através de mecanismos de introjeção, tornando-se mais reativas a determinados comportamentos. Norbert Elias, na construção de sua teoria do processo civilizatório observou que em determinadas sociedades ocidentais mas, especialmente na Inglesa, onde diga-se de passagem também surge a forma moderna de esporte, "o domínio da conduta e da sensibilidade tornou-se mais rigoroso, mais diferenciado e abrangendo tudo, mas, também, mais regular, mais moderado e banindo quer excessos de punição quer de autocomplacência" (1992:41). Neste contexto, o esporte moderno tem aparecido como um veículo privilegiado para a promoção de uma certa moralidade pública e de um padrão de autocontrole ${ }^{4}$. Com efeito, o Olimpismo de Pierre de Coubertin, desenvolvido no final do século XIX e início do século $\mathrm{XX}$ e que é por nós entendido como ideologia particular de prática esportiva ${ }^{5}$, deu forma intelectual a estas preconizações. Na verdade, ciente de que o excesso é uma característica da competição e do caráter neutro do esporte, ou seja, que sua positividade ou negatividade está diretamente relacionada ao conjunto de valores que condicionam sua prática, Coubertin esteve permanentemente preocupado com a elaboração deste conjunto ${ }^{6}$. Isto é particularmente importante na medida em que foi a expansão objetivada do movimento olímpico um dos principais elementos de globalização de um determinado conjunto de formas, crenças e sentidos de prática esportiva preponderante durante os setenta primeiros anos do século XX (Donnelly, 1995; Grupe, 1992 eLenk, 1976).

Em resposta a esta situação, o uso de drogas e de determinados procedimentos que aumentem o rendimento físico do atleta passou gradualmente a 
ser considerado imoral e, na esfera do esporte organizado, ilegal. Tendo sempre os Jogos Olímpicos como referência, é interessante lembrar que em suas primeiras edições modernas o doping era raro mas não ilegal, tanto que uma das misturas dopantes mais usadas consistia em um coquetel com cocaína, cafeína e estricnina ${ }^{7}$. Do mesmo modo, até o início do controle médico em 1968, era raro mas não impossível que atletas usassem anfetaminas e posteriormente à Segunda Guerra Mundial, esteróides anabólicos (DeRose, op.cit.).

De maneira não-exaustiva, é possível dizer que em face das qualidades educativas historicamente tributadas ao esporte, de seu crescente valor econômico e da transformação das drogas e psicotrópicos em uma questão social controversa, o doping foi se tornando cada vez mais uma problemática sensível no campo do esporte. Neste sentido, são igualmente crescentes as instituições, organismos e políticas destinadas a combater o uso de determinadas substâncias e procedimentos definidas como auxílios ilegais ao desempenho humano ${ }^{8}$. Todavia, um problema sempre presente, e central para este artigo, é o de se determinar o que pode ou deve ser caracterizado como doping ou não. Este é o tipo de questão que comporta abordagens técnicas (se uma dada droga ou processo auxilia de alguma forma o rendimento e/ou é potencialmente perigosa para a saúde), sócio-culturais (se uma determinada prática ou hábito cultural particular se coaduna e em que nível com um sistema institucional mais geral), éticos (havendo uma ou mais éticas do esporte, em relação a quais delas o doping configurase como uma transgressão) e políticos (quem possui legitimidade suficiente para determinar o que seja o doping assim como para organizar seu controle e as formas de punição), sempre permeados de uma certa tensão inerente aos processos com um número maior de variáveis. Em face destas irresoluções, de acordo com a Declaração Final da Conferência Mundial sobre Doping no Esporte (1999), o doping é definido como:

"o uso de um artificio, substância ou método, potencialmente perigoso para a saúde do aúeta elou capaz de aumentar sua performance, ou a presença no corpo do atleta de uma substância ou a constatação do uso de um método presente na lista anexa ao Código do Molimento Olimpico And-Doping".

Um primeiro exame desta definição revela que ela é constituída de argumentos que podem ser divididos em três tipos: (a) um argumento de ordem técnico/ cientifica; (b) um argumento de ordem ética; (c) um argumento assilogístico'. A definição de doping como substância ou método potencialmente perigosos para a saúde é o que chamo de argumento técnico/ científico. Possui raízes no discurso médico, um tipo de discurso de intervenção freqüentemente de ordem moral, porém quase sempre revestido de cientificidade. Neste sentido, parte da premissa que as evidências técnicas que $\mathrm{o}$ fundamentam são suficientes para legitima-lo como um regulador do comportamento individual e social. Em segundo lugar aparece um argumento de ordem ética. Com efeito, como já discuti em outro texto (Tavares, 1999b), a caracterização do doping como um artifício capaz de aumentar a performance, embora, como veremos adiante, contraditória à própria natureza do esporte tradicional, parece estar baseada de alguma forma no conceito de fair play como uma representação idealizada do ethos cavalheiresco do esporte vitoriano. Neste sentido, o aumento da performance parece ser entendido como algo que ofenda uma ética fundamental do esporte. A terceira parte desta definição configura-se como uma definição de elevado pragmatismo. Ao estabelecer que são doping os métodos e substâncias presentes em um index proibitório, em última análise está se dizendo que é doping o que é ou for considerado doping pelos órgãos legitimamente dispostos a declará-lo. Desta maneira o critério de validade fundamenta-se primariamente no consenso atingido pelas instituições que tem o controle sobre o tema. Uma construção arbitrária que impede qualquer tentativa de exame de seus argumentos dentro dos limites deste texto, uma vez que nos obrigaria a discutir pontualmente cada uma das substâncias e métodos presentes na referida lista. 
Sob o prisma da ética do esporte, a questão do doping está intrinsecamente ligada à noção do 'jogo justo' e por conseguinte a um conjunto de comportamentos genericamente encapsulados no conceito de fair play. Assim, me parece importante que primeiramente examinemos, ainda que rapidamente, o conceito de fair play. Em segundo lugar, em face das implicações relativas ao tipo de comportamentos regulados pelo conceito de fair play e suas implicações com a questão do doping, examinarmos algumas distinções sobre a natureza das regras no esporte.

\section{Conceitos de fair play}

De uma forma bastante genérica, o fairplay é entendido em um plano mais geral como uma atitude de prática esportiva moralmente boa. Neste contexto, o termo 'fairplay tem se revelado um campo amplo o suficiente a interpretações diversas de seu significado. Uma iniciativa bastante comum é traduzi-lo como 'jogo limpo' ou qualificálo como 'espírito esportivo'. Estas expressões revelam-se contudo bastante limitadas na medida em que não avançam no sentido da elucidação do conceito. Ou seja, não estabelecem um campo demarcatório onde se reconheçam que normas e atitudes o caracterizam.

Segundo Lenk (op. cit.), o fairplaypode ser entendido como um valor dotado de uma dupla natureza. Assim, ele se divide em duas categorias, o fair play formal e o fair play nao-formal. O fair play formal, relaciona-se objetivamente ao cumprimento de regras e regulamentos que o competidor, em princípio, tem que cumprir, podendo ser assim considerado como uma "norma-obrigação" (Lenk, ibid.: 137). Não parece ser difícil encontrar maneiras de exemplificar esta natureza do fair play uma vez que, ainda que atos de indisciplina, violência, violações à regra e reclamações ocorram com freqüência, o princípio do respeito as regras esportivas permanece sendo a base comum ao desenvolvimento de qualquer disputa esportiva, constituindo-se em um 'acordo' prévio necessário para a exis-

\section{4}

tência do próprio jogo.

Já o fair play não-formal, estende-se além do campo das regras e regulamentos. Diz respeito, em princípio, ao comportamento esportivo baseado nos valores morais do praticante. Na medida de sua realização subjetiva, esta categoria do fair play é também difusamente definida. Ao contrário do fair play formal, claramente delimitado pela própria existência das regras esportivas, o fair play nãoformal se realiza "recusando vantagens injustificáveis" (Grupe, op. cit.). Segundo o Código de Ética Desportiva do Conselho da Europa (1996), o fair play,

\footnotetext{
"Cobre as noções de amizade, de respeito pelo outro, e de espirito esportivo, representa um modo de pensar, e não simplesmente um comportamento. O conceito abtangea problemática da luta contra a batota, a arte de usar a astúcia dentro do respeito as regras, o doping, aviolencia (tanto fisica quanto verbal), a desigualdade de oportunidades, a comercialização excessiva ea corrupção".
}

A natureza subjetiva do fair play não-formal tem dado margem a interpretações mais ou menos rigorosas do que seria este "modo de pensar" ou estas "vantagens injustificadas", o que tem levado muitas vezes ao entendimento do fair play como um comportamento esportivo verdadeiramente altruís-tico, recusando por exemplo, a vantagem obtida graças a um erro da arbitragem ou um acidente de percurso sofrido por um adversário ${ }^{10}$.

$\mathrm{Na}$ verdade podemos perceber que alguns comportamentos de fair play não-formal são mais freqüentes em um esporte do que em outros ${ }^{1}$. No futebol por exemplo, ele pode ser facilmente exemplificado pelo ato do atleta que joga a bola para fora do campo de maneira a permitir que um companheiro de jogo contundido, mesmo do time adversário, possa receber atendimento médico. No entanto, este não parece ser um exemplo válido para o basquete. Também é difícil imaginar que um velocista interrompa sua participação numa prova para auxiliar um companheiro caído. Os exemplos

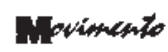

Movimento

Porto Alegre,

V.

2002 
particulares poderiam ser multiplicados aqui pelo número de modalidades existentes. Isto parece demonstrar que cada esporte desenvolve dentro de sua tradição uma maneira própria de articular seu valores éticos, com seus valores técnicos e estéticos ${ }^{12}$. Embora na história dos esportes registrem-se diversos casos de atletas que se comportaram de maneira verdadeiramente altruística, este comportamento de fair play é inegavelmente menos comum de ser observado, na medida em que é, na maioria das vezes, intangível por regras escritas ainda que seja legitimado culturalmente. Ou seja, é válido dizer que embora um comportamento compatível com a idéia de fair play não-formal é, até certo ponto, uma expectativa presente entre jogadores e público esportivo, sua realização depende muito mais de valores morais subjetivamente significados.

Em síntese, a noção de um fair play formal tal como proposta Lenk, equivale a uma estrutura conceituai necessária para a realização do esporte na prática, traduzida na forma de regras e sua funcionalidade e que à ela os indivíduos aderem livremente. No entanto, ainda que a adesão a um conjunto formal de regras seja necessária a própria realização do jogo/esporte, ela não fornece em si nenhuma razão moral que abstenha um jogador da violação às regras do jogo. Pelo contrário, esta demarcação (entre o que é permitido e o que não é) pode ser interpretada como o oferecimento de escolhas, entre a obediência estrita as regras ou sua quebra, inaceitável mas ainda assim possivel, ao preço de certas sanções. As próprias regras ao estipularem diferentes sanções para diferentes violações, oferecem a necessária referência para uma tomada de decisões ${ }^{13}$. O doping embora prima facie possa ser entendido como a negação do fair play do tipo não-formal, tem sido crescentemente tratado pelo prisma da legalidade. Neste contexto, parece importante observar uma tipologia das regras esportivas para compreender sob que tipo de regras esportivas e sob que tipo de fair play o doping deve ser compreendido.

\section{Uma tipologia das regras no esporte}

Os jogos são práticas governadas por regras. Basicamente, as regras são o que definem a própria prática do jogo. Neste sentido, as regras dos jogos podem ser divididas em dois tipos: as regras constitutivas e as regras regulatórias ${ }^{14}$.

Segundo Klaus Meyer (apud McDonald, 1997), as regras constitutivas são aquelas que definem o que é um jogo. Determinam exatamente o objetivo do jogo e os meios pelos quais através de prescrições e proscrições ele será atingido. Também apresentam uma estrutura descritiva, definindo O uso ou não de características em termos substâncias e de instalações e procedimentos dopan

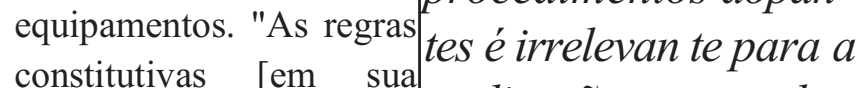
$\begin{array}{ll}\text { constitutivas [em sua } & \text { nande maioria] não } \\ \text { realização mesma de }\end{array}$ determinam o que os um determinado jogadores devem fazer esporte. Ou seja, em mas constituem otermos da tipologia conceito da ação per-das regras esportivas, mitida, prescrita ou o doping não ofende proibida e tem então a forma lógica de ' $\mathrm{X}$ conta as regras que como Y no contexto C' caracterizam e (Loland, op. cit.: 84). Jálregulam a realização as regras regulatórias são de uma dada prática aquelas que "especificam o tipo e al esportiva. severidade das penalidades a serem aplicadas quando uma regra constitutiva qualquer tiver sido violada" (Meyer apud McDonald, op. cit.: 2). Posteriormente um terceiro tipo de regras, as regras auxiliares foi proposto por Klaus Meyer. Segundo este autor, estas regras são aquelas destinadas a regular/limitar a conduta fora do campo de jogo. Estas regras são definidas como "restrições ou qualificações externas, contingentes e suplementares, adicionais à uma atividade pré-existente já definida por suas regras constitutivas e regulatórias" (ibid.: 3$)^{15}$.

Em face destas distinções entre tipos de fair playe 
tipos de regras, parece ser possível dizer que o doping se situa numa situação de fronteira. Uma vez que normas descritivas não podem servir como premissas para conclusões normativas, seu uso parece ser facilmente classificável como um tipo de comportamento regulado por regras de tipo auxiliares. Isto permite dizer que o uso ou não de substâncias e procedimentos dopantes é irrelevante para a realização mesma de um determinado esporte. Ou seja, em termos da tipologia das regras esportivas, o doping não ofende as regras que caracterizam e regulam a realização de uma dada prática esportiva. Isto explica porque sujeito a um conjunto normativo concreto o doping é entendido como uma questão subjetivamente significada. Para um jogador mais preocupado em atingir o máximo de realizações em sua carreira do que com o processo do próprio jogo, o uso do doping pode ser uma estratégia racional. No entanto, pode esta estratégia racional ser justificada sob um ponto de vista moral? Parece-nos que baseados em uma interpretação conservadora do que seria a ética do esporte, a resposta tem sido não. E baseado principalmente neste tipo de compreensão que são erigidos os principais argumentos contra o doping.

\section{Examinando os argumentos anti-doping}

\section{Primeiro argumento: O doping é potencialmente perigoso para a saúde}

Nos dias atuais, o argumento da ameaça à saúde pelo uso de drogas parece ser aquele que demonstra ter maior força e visibilidade. Numa sociedade crescentemente medicalizada, com forte orientação para a saúde e uma também crescente recusa ao envelhecimento, não surpreende que antes de mais nada, a primeira justificativa no combate ao doping esteja baseada numa questão de saúde. Apesar de em casos como o dos esteróides anabólicos androgênicos ser conhecido que a interrupção do uso reverta seus efeitos danosos, reconhece-se o risco potencial para a saúde de uma série de substâncias atualmente capituladas como doping ${ }^{16}$. Todavia, como foge ao esco- po deste trabalho discutir especificamente os efeitos sobre a saúde desta ou daquela substância, mas nos concentrar nos argumentos que justificam a proibição de uso no esporte de uma série delas, perguntase: é o fato destas drogas e/ou procedimentos serem potencialmente perigosas para a saúde o que as torna condenáveis? Se assim o for então é necessário explicar aos milhões de praticantes do esporte mundo afora porque sendo o doping proibido pelos seus riscos para a saúde, as bebidas alcoólicas e o cigarro continuam permitidos, o que não é algo fácil. Há um número comparativamente maior de evidências que comprovam os malefícios do cigarro para a saúde e no entanto as restrições à sua venda são mínimas, quando existentes. Muito pelo contrário, por diversas vezes as indústrias do tabaco se utilizam de imagens e contextos esportivos para a promoção de suas marcas com a cálida complacência dos organismos esportivos nacionais e internacionais.

De maneira idêntica também a indústria de bebidas, a despeito dos fatos que apontam para os problemas sócio-econômicos associados ao álcool, tornando-se por vezes uma questão de saúde pública, recebe pouca ou nenhuma atenção dos indivíduos preocupados na promoção de uma moralidade esportiva quando associam suas marcas à atividades esportivas ${ }^{17}$. Há, é claro, imensos interesses comerciais em jogo nesta questão, mas pode-se pensar que os grupos farmacêuticos também são suficientemente fortes e estão potencialmente interessados em auferir grandes lucros com a venda indiscriminada do que hoje é restrito.

Como não se trata aqui de erigir dilemas do tipo "ou instaura-se a decência ou locupletemo-nos todos"18, deixemos de lado comparações que parecem fáceis e observemos à própria prática esportiva. Não parece ser mais um fato controverso a constatação de que quanto maior o nível de exigência do esporte de alta competição maiores são os riscos potenciais à saúde dos próprios praticantes. Neste contexto, o caso do boxe é o mais evidente. Embora não possua os dados, penso ser pouco provável que a grande maioria das substância dopantes somadas tenha causado tantos 
males à saúde de seus usuários quanto o boxe. Este é um dos poucos esportes que tem por objetivo específico a ruína física do oponente, e no entanto, embora seja potencialmente perigoso à saúde, com a exceção dos poucos países em que é proibido, não parece estar no horizonte das preocupações de muitas pessoas uma campanha para banimento do boxe da mesma maneira que se faz com o doping.

O que é evidente no boxe, também é bastante verdadeiro para um sem-número de outros esportes. Não faz muito tempo, não foi o próprio Oscar Schmidt, nosso jogador de basquete mais famoso e bem sucedido que afirmou que a dor fazia parte do seu uniforme? Certamente a atividade física envolve um certo risco para a saúde que é tanto maior quanto maiores forem as exigências físicas envolvidas na atividade praticada. Também é certo que outras atividades não-esportivas também envolvem riscos e acidentes físicos. Todavia, a quantidade de lesões, dores, inchaços, torções e fraturas que vivenciam os atletas de alto nível durante sua carreira esportiva, torna risível a idéia de que o doping deve ser proibido simplesmente porque pode causar mal à saúde.

Por último, é importante observar que o argumento do risco potencial à saúde gera uma série de questões práticas ainda em aberto. Veremos rapidamente alguns deles aqui. Por exemplo, qual posição deve ser tomada se um atleta tem razões médicas para tomar uma droga em particular que é todavia proibida pelos regulamentos anti-doping? Um primeiro problema é saber se as alegações de uso médico são verdadeiras. Neste ponto a história do esporte mostra que por diversas vezes a ética médica se torna o elemento em questão. Por exemplo, nos Jogos Olímpicos de 1984, as comissões médicas dos Estados Unidos e da Suíça forneceram atestados indicando que todos os atletas de suas equipes de pentado moderno necessitavam utilizar beta-bloqueadores por razões de saúde. Neste caso, considerando que a prática médica não é uma ciência exata, a efetivação do contraditório é sempre um risco a ser assumido.

Uma segunda e mais complexa questão é saber se, sendo possível determinar que o uso de determinada droga proibida é necessária à um dado atleta, isto legitima seu uso no esporte. Qual o critério a ser adotado? Sem se precisar exatamente qual a diferença entre a necessidade de uso e o fator de ganho obtido pelo atleta com a ingestão de determinado produto, qual seria a decisão mais justa e adequada? Permitir que ele compita usando por motivo de saúde algo que aos outros é proibido? Ou impedi-lo de participar justamente por usar algo sem o qual ele não pode competir em condições de igualdade?

\section{Segundo argumento: $O$ doping melhora o desempenho esportivo}

Deixemos de lado aqui a discussão sobre a efetividade ou não das substâncias usadas e dos procedimentos tomados para melhorar o desempenho atlético. Certamente algumas delas efetivamente melhoram direta ou indiretamente a performance. Outras, embora de efeito incerto, despertam a crença em sua efetividade, o que sob um argumento puramente psicológico também podem até mesmo causar uma melhora de resultados. A questão é: este é um argumento suficiente para se justificar a proibição do uso de determinadas drogas? ${ }^{19}$

Pode parecer simplório dizer mas, apropria natureza do treinamento esportivo é tão somente uma questão de melhora do desempenho. Isto significa dizer que, dentro de uma lógica discriminante, este argumento inicial, tomado em toda simplicidade de sua formulação, não é suficientemente eficiente. A melhora do rendimento, em seus mais variados aspectos, é uma condição intrinsecamente ligada à própria natureza da competição esportiva tomada como processo. Assim, se o esporte de alto nível vive da busca constante da superação do desempenho, por que um artefato que conviesse a realização deste elemento central da prática esportiva seria, em si mesmo, algo errado e condenável?

Por outro lado, colocados ainda sob o mesmo aspecto, tênis, roupas, bicicletas, varas de salto e uma série de outros equipamentos também são especialmente projetados para melhorar o desempenho atlético. Um 
exemplo recente e famoso é o da fast skin, a vestimenta de nado conhecida no Brasil por 'Pele de Tubarão'. A questão inicial era exatamente saber se e quanto esta vestimenta poderia melhorar o desempenho dos nadadores que a vestissem. Antes dos Jogos Olímpicos de Sidnei (2000), uma série de argüições e objeções foram levantadas junto à Federação Internacional de Natação (FINA) e ao Comitê Organizador dos Jogos Olímpicos de Sidnei (SOGOC) pedindo a proibição de seu uso baseados exatamente na possibilidade desta vestimenta atuar como um auxílio ao rendimento, i.e. como uma forma de doping. Conforme sabemos, seu uso está permitido baseado na premissa de que sua qualidade central é a de diminuir a resistência à passagem do fluxo de água junto ao corpo do atleta, diminuindo então um obstáculo à um melhor rendimento e não melhorando o rendimento atlético propriamente dito, como faria, por exemplo, no caso da corrida, uma sapatilha.

Em contas finais, no que se refere às condições hidrodinâmicas ideais de nado, os adetas deveriam nadar nus, o que não é permissível de acordo com imperativos morais, sociais e econômicos vigentes. Não seria então o caso de se perguntar se, diante de um conjunto tão grande de interdições que não permitem aos adetas outra escolha se não vestir algo, a distinção entre auxílio ao desempenho' e 'eliminação de obstáculo' perde, pelos efeitos práticos, sua validade? Antes que uma resposta seja obtida é necessário que se observe porém que, se é possível mensurar com razoável fidedignidade a melhora da performance ou não em função dos implementos utilizados, é extremamente difícil determinar se nas condições objetivas e pontuais de uma determinada prova, o sucesso ou o insucesso foi significativamente determinado pelo uso de determinado implemento.

A idéia de que o uso de drogas é moralmente errado simplesmente porque elas funcionam como um potencializador do desempenho é dificilmente sustentável quando colocada em confronto com as conseqüências práticas do uso de outros elementos acessórios à prática esportiva. Ainda assim, de maneira bastante diferente do que se entende e se sanci- ona habitualmente como doping, o uso de implementos objetivamente desenvolvidos para proporcionar um aumento de rendimento não tem sido considerados como ajuda injusta e/ou ilegal.

\section{Terceiro argumento: O doping é uma ajuda artificial ao desempenho}

Este argumento, é na verdade um desdobramento e/ ou um aprofundamento do argumento anterior. Mas o que se quer dizer exatamente com a palavra 'artificial' aqui? Considerando que o ser humano se diferencia do mundo natural pela realização do trabalho e pela produção da cultura, qualquer implemento usado para o desenvolvimento das condições físicas necessárias ao progresso atlético é, necessariamente, artificial. Neste sentido, por exemplo, não seria o caso de se perguntar provocativamente se o processo de hipertrofia muscular através de equipamentos de exercício contra a resistência é de alguma forma natural? Com efeito, é necessário reconhecer que da mesma maneira que muitas drogas proibidas, muitas drogas permitidas são tão artificiais quanto. Ou seja, são preparações elaboradas intencionalmente para a obtenção de um efeito qualquer impossível ou quase de ser atingido pelas próprias condições orgânicas humanas. Assim, se o critério a ser estabelecido é o da 'des-natureza' do elemento tomado, então teríamos muitas dificuldades em separar e justificar a legitimidade do uso ou não das vitaminas, dos esteróides anabólicos e da testosterona, para ficarmos aqui em apenas poucos exemplos.

Por outro lado, como já examinamos anteriormente, uma série de implementos, 'necessários' à prática esportiva, são especificamente projetados para, a partir de sua configuração, ampliarem as potencialidades presentes no gesto esportivo humano, ajudando artificialmente o desempenho. Tomemos dois exemplos. Diferentes materiais e formas construtivas podem permitir que a vara da prova atlética do salto apresente diferentes reações à ação mecânica do saltador no momento da prova, fazendo com que um implemento com maior capacidade de reação mecânica ofereça ao atleta um empuxo maior 
e, por conseguinte, uma vantagem competitiva no ato de saltar. Do mesmo modo por exemplo, para muitos, o desempenho e as medalhas obtidas pela equipe americana de ciclismo nos Jogos Olímpicos de Los Angeles (1984) tiveram muito a ver com as bicicletas de alta tecnologia ${ }^{20}$ que aquela equipe usou naquelas competições, levando atletas de desempenho menor a auferirem resultados acima de suas possibilidades. No entanto, mesmo a partir das mesmas conseqüências práticas, implementos físicos e ajudas químicas ocupam patamares diferentes no conjunto das preocupações e ações normativas dos sujeitos ligados à prática esportiva.

Em síntese, parece-nos que o conceito de ajuda artificial ao desempenho como algo eticamente condenável necessita de uma melhor elaboração de forma a no futuro instituir melhor a distinção que se espera dele aqui.

\section{Quarto argumento: O doping 'desloca'a competição da arena esportiva para os laboratórios}

Um outro argumento de natureza ética contra o doping é aquele que afirma que o processo de desenvolvimento de substâncias dopantes transforma a competição esportiva em uma verdadeira competição entre laboratórios de farmacologia, de tal maneira deslocando-a de seu lugar privilegiado e/ou natural. Se tal afirmativa pode ser aceita como válida, do mesmo modo também deve-se aceitar como verdadeira a idéia de que o desenvolvimento das tecnologias aplicadas ao moderno treinamento esportivo podem ser entendidos como uma verdadeira competição entre fisiologistas, profissionais de educação física e psicólogos, entre tantos e tão diversos profissionais, em seus serviços, centros de treinamento, laboratórios de fisiologia e psicologia aplicados ao desenvolvimento do desempenho humano. Do mesmo modo que os farmacologistas, estes também estão preocupados com o desenvolvimento de elementos que permitam aos atletas a potencialização de sua performance. $\mathrm{O}$ mesmo argumento pode ser aplicado ao desenvolvimento contínuo de uma série de equipamentos esportivos. A corrida pela construção de equipamentos cada vez mais propícios à melhora do rendimento também pode ensejar que se compreenda o esporte de alta competição como um torneio entre sistemas de desenvolvimento tecnológico, ou como se tem observado mais recentemente, entre empresas de material esportivo. Deste modo, aqueles que estão preocupados com o deslocamento da competição da arena esportiva para os laboratórios, deveriam, quem sabe, responder porque as pesquisas desenvolvidas nos laboratórios de farmacologia são menos válidas do que aquelas desenvolvidas em laboratórios de fisiologia do exercício, centros de treinamento esportivo ou indústrias de material esportivo, por exemplo.

Por outro lado, a idéia de competição deslocada de seu lugar privilegiado gerou um volume bastante extenso de críticas ao esporte de competição de um modo geral e aos Jogos Olímpicos em particular tendo como base a percepção da arena esportiva como um locus de confrontação entre países e sistemas ideológicos. Isto foi tão mais verdadeiro quanto era presente a disputa geo-política da 'Guerra Fria'. No entanto seria ilusório acreditar que, mudada a configuração mundial entre os países, tornou-se inexistente ou inaplicável o conceito de representação da potencial nacional através do esporte. O recente debate instalado no Brasil a respeito do desempenho alcançado nos Jogos de Sidnei demonstra que ainda é perfeitamente válida a idéia de que a competição adética não é apenas algo entre indivíduos ou equipes mas entre representantes de sistemas sócio-econômicos. Conseqüentemente, tais sistemas podem ser, e freqüentemente são, julgados pelos resultados que seus atletas produzem. Isto eqüivale a dizer que a melhora do rendimento adético não é uma questão que possa ou deva ser deixada exclusivamente sob a responsabilidade do adeta e seu apoio mais direto, mas que deva ser entendida como uma função dos valores e recursos de toda uma sociedade. A este respeito, uma comparação entre os resultados olímpicos e dados do índice de Desenvolvimento Humano 2000 do Programa das Nações Unidas para o Desenvolvimento (PNUD) confirma que o desenvolvimento humano é condição necessária, mas não suficiente para o bom desempenho esportivo. Segundo o filósofo in- 
glês contemporâneo Jim Parry (1997), sob o ângulo da competitividade deslocada, as competições internacionais podem ser consideradas como fortemente injustas, na medida em que os países possuem condições desiguais de recursos materiais e de conhecimento, inclusive para produzir drogas cada vez mais eficientes e capazes de não serem detectadas pelos controles anti-doping. E interessante observar aqui que em pesquisa que conduzimos junto aos atletas brasileiros que foram aos Jogos Olímpicos de Atlanta (Tavares, 1998), um dos argumentos centrais daqueles indivíduos que se posicionavam contrariamente ao uso de doping era exatamente o da diferença tecnológica entre os países desenvolvidos e não desenvolvidos. Na visão pragmática da maioria dos atletas brasileiros em Atlanta 1996, a proibição do uso de substâncias consideradas dopantes é a situação menos adversa. A possibilidade de liberação de uso do doping é claramente entendida como a possibilidade de utilização de todo o potencial tecnológico ao alcance dos países ricos sem as peias de ordem ética e legal, o que tornaria ainda maiores a diferença nas condições de preparação entre adetas de países desiguais. Em face deste contexto e tendo como referência o argumento da competição deslocada, Parry pergunta provocativamente: "deveríamos então banir as competições internacionais?"

\section{Quinto argumento: O uso de doping por alguns força outros a usá-lo}

Está além do escopo deste texto examinar o argumento da negação da liberdade da ação humana implícito neste enunciado. Por outro lado, nos parece que a idéia de que alguém pode fazer alguma coisa motivado pela possibilidade que outra pessoa também o faça, pode ser melhor explicada no conceito do "jogo da garantia", originário da teoria dos jogos. Se considerarmos que o 'contrato voluntário' a que estão submetidos todos os participantes cria uma forma de limitação racional e voluntária às premissas não necessariamente morais das estratégias e escolhas racionais, a moralidade da ação se transforma em uma estratégia que se amolda a diversos a priori. O que está colocado aqui é a situação que Breivik (1992) chamou de "doping game", o jogo do doping. Um dilema em que o atleta tendo a opção de fazer ou não uso de doping, coloca-se em comparação com seus concorrentes diretos que, ele sabe, também tem uma das duas opções a fazer. Assim, diante de quatro possibilidades de situação (eu não uso/eles não usam; eu uso/eles usam; eu uso/eles não usam; eu não uso/eles usam), o uso do doping se torna uma boa opção caso se tenha dúvida, ainda que ínfima, sobre a vontade de adesão ao 'contrato' dos outros competidores ${ }^{21}$.

Também é baseado neste tipo de argumento, embora alguns desconheçam seus fundamentos, que para muitos a coerção e não a educação é o único caminho possível de combate ao problema do doping. Segundo este tipo de raciocínio, os atletas ainda que estejam interessados em não utilizar artifícios dopantes, se não forem forçados a cooperar, por coação de uma 'lei moral' de tipo Rousseauniano ou por uma outra forma de coação externa, podem efetivamente sentirse tentados ou forçados à transgressão, inclusive baseados em motivos bastante racionais.

No entanto, ainda que o enunciado do argumento do tenha uma alta cota de razoabilidade, é isto que torna o doping algo imoral? Todo adeta de alto nível sabe o quanto é necessário de treino para se atingir um nível excelente de competitividade. Uma boa parte do volume de treinamento necessário para se atingir um nível mais alto hoje em dia pode ser explicado, da mesma maneira que o doping, pela teoria dos $\operatorname{jogos}^{22}$. Não existe outra opção para aquele que quer chegar ao alto nível que não seja treinar no nível que ele imagina ou sabe que todos estão treinando. Assim, é perfeitamente possível dizer que se uso de doping é imoral pelo fato de forçar aqueles que não o querem a usá-lo, então da mesma maneira é imoral o nível de treinamento hoje requerido. De fato, para muitos críticos do esporte moderno, o nível atualmente alcançado força a maioria dos atletas ao supertreinamento, ameaçando sua dignidade humana por sujeitarem estas pessoas a esforços físicos excessivos, além de impedirem seu desenvolvimento pleno como pessoa, intelectualmente e moralmente. Deveríamos então, por uma forma de coação externa, impedir o treinamento de alta intensidade? 


\section{Conclusão}

Tem feito parte do mundo da modernidade a crença na possibilidade e a ambição do estabelecimento de uma ética universalista. Como parte desta tradição, o esporte, em suas mais diversas feições, e de maneira explícita no Olimpismo, tem advogado a existência de "valores éticos fundamentais universais" (IOC, 2001:1). Este universalismo pressupôs a construção de uma ética da prática esportiva também universal destinada a transformar o esporte em uma atividade moralmente boa. Neste contexto, a idéia de fair play como uma codificação de comportamentos se tornou em sua origem um ideal dominante e um valor de controle para o esporte moderno. Contudo, especialmente na dimensão do esporte de rendimento e do esporte-espetáculo, o equilíbrio entre a orientação para o desempenho e seus valores orientadores de controle tem experimentado tensões cada vez maiores. A crescente ocorrência do uso de substâncias dopantes no ambiente de alta competição exemplifica, mais do que qualquer outra, estas tensões.

Como tentei demonstrar, uma vez que os argumentos anti-doping são baseados claramente em premissas normativas científicas, éticas ou de autoridade, o deslocamento dos sentidos, formas e dos valores sociais das práticas esportivas terminam por gerar inconsistências entre suas formulações e suas conseqüências práticas. Ou seja, ainda que sejam verdadeiros os argumentos anti-doping, eles não suficientes. Neste contexto, o descasamento entre a norma e os valores subjetivamente significados pelos praticantes (fair play não formal) favorece a compreensão que apenas punição e controle ao invés de argumentação e educação são os caminhos possíveis de combate ao doping. Sob o ponto de vista da intervenção este parece ser o caminho mais plausível, quase inevitável.

Todavia, penso que os argumentos técnico-científicos e éticos do discurso anti-doping deverão ser superados em algum momento por uma abordagem voltada para uma essência simbólica da prática es- portiva. A busca da excelência e da (auto) superação presentes no esporte de alta competição representam de alguma forma a tentativa de obter uma resposta a questões de ordem ontológica: qual o limite da realização de uma proeza física da espécie humana? Que ponto máximo de desempenho podemos atingir com o nosso corpo? Qual é o nível de excelência da performance humana? Me parece que estas questões subliminarmente presentes na prática esportiva são o móvel último deste fenômeno social impressionante que é o esporte. Isto não significa dizer que a questão do doping pode assim ser superada, ou que a necessidade de controle e punição deixe de existir. Apenas entendo que o doping como um problema se situa numa dimensão mais profunda que a dos princípios normativos da ação que seus argumentos exemplificam.

Para mim, estas são questões fundamentais. Talvez possamos traçar um paralelo aqui com os enfrentamentos vivenciados nos últimos anos pela bioengenharia e pela engenharia genética no campo da moral e da ética. A discussão de fundo nestas áreas é sobre os limites do que entendemos ser o humano. Do mesmo modo, em face de sua dimensão ontológica, não serão os argumentos normativos, de todo insuficientes, que irão delimitar esta discussão. Levando este paralelo adiante é possível dizer que, no campo do esporte, o doping pode ser aceitável até certo ponto. Com efeito, se olharmos para o futuro com os olhos do presente, em um cenário de crescente intervenção artificial sobre ávida e mesmo de alguma perda da distinção entre o artificial e o natural, não há porque não acreditar que alguns procedimentos de ajuda artificial ao rendimento tenham grandes chances de se tornarem legais.

Todavia, uma pergunta final pode aparecer. Se a comparação entre as premissas dos argumentos antidoping e suas conseqüências práticas demonstra que os problemas do doping são também, por vezes, os problemas do próprio esporte, por que insistir no uso destes argumentos? Talvez porque para muitos, o esporte de rendimento, de espetáculo e olímpico, apesar de todos os seus dramas, vícios e problemas 
ainda seja, como diz MacAloon (1984:243), "as ocasiões nas quais, como uma cultura ou uma sociedade [e como indivíduos, eu acrescento] nós reproduzimos e definimos a nós mesmos, dramatizamos nossos mitos coletivos e história". Neste sentido, é como se o esporte devesse ou pudesse ocupar o lugar de uma reserva moral coletiva, oferecendo um espaço de representação positiva da sociedade e um acervo de exemplos positivos. Uma posição emblemática para os indivíduos e a sociedade que ajudasse a reconhecer de maneira sensível, prática e imediata um pouco do que somos e temos de melhor. Para mim, o que o doping coloca de maneira inelutável em jogo, quando confrontado com a dimensão simbólica do esporte, é o verdadeiro limite do humano na competição física ${ }^{23}$.

\section{Referências Bibliográficas}

ABBAGNANO, Nicola. Dicionário de Filosofia. São Paulo: Martins Fontes, 1998.

BREIVIK, Gunnar. 'Doping Games. A Game Theoretical Exploration of Doping'. International Review for the Sociology of Sport 27/3 (1992).

CONSElHO DA EUROPA. Código de Ética Desportiva. Oeiras: Câmara Municipal de Oeiras, 1996.

DaCOSTA, Lamartine P. 'O Olimpismo e o Equilíbrio do Homem'. In: Tavares, O., DaCosta, L.P. (eds.) Estudos Olímpicos. Rio de Janeiro: Editora Gama Filho, 1999, pp.5069.

DeROSE, Eduardo. 'Sports Medicai Problems of the Top Elite Athletes'. In: INTERNATIONAL OLYMPIC ACADEMY. International Session of the International Olympic Academy, 35., The IOC Centennial Congress - The Congress of Unity. Analysis and Reflections. Report... International Olympic Academy: IOA, 1995. p. 56-62.

DONNELY, Peter. 'Prolympism: sport monoculture as crisis and opportunity', Quest, Vol.48,
No.1, pp 25-42, 1996.

ELIAS, Norbert \& DUNNING, Eric. A Busca da Excitação. Lisboa: Difel, 1992.

GEBAUER, Gunter. 'Citius-Altius-Fortius and the Problem of Sport Ethics: a Philosopher's Viewpoint'. In: Landry, F. et alii (eds.) Sport... The Third Millennium, Quebec: Les Presses de 1'Université Laval, 1992. p.467-476.

GOMES, Marta. 'Solidariedade e Honestidade: Os fundamentos do Fair Play entre adolescentes escolares'. In: Tavares, O., DaCosta, L.P. (eds.) Estudos Olímpicos. Rio de Janeiro: Editora Gama Filho, 1999, pp. 207-222.

GRUPE, Ommo. 'The sport culture and the sportization of culture: identity, legitimacy, sense and nonsense of modern sport as a cultural phenomenon'. In: Landry, F. et ai. (eds.) Sport... The Third Millenium. Quebec: Les Presses de l'Université Lavai, 1992, pp. 135-146.

HATFIELD, Frederich C. Esteróides Anabólicos. In Sprint, ano V, n. 6, nov/dez 1996 e ano VI n. 1, jan/fev 1997.

INTERNATIONAL OLYMPIC COMMITTEE (IOC). Olympic Charter [online]. Disponível em: www.olympic.org. [capturado em 31 ago. 2001].

LALANDE, André. Vocabulário Técnico e Crítico da Filosofia. São Paulo: Martins Fontes, 1993.

LENK, Hans. 'Toward a social philosophy of the Olympics: values, aims and reality of the modern olympic movement'. In: Graham, P.J. e Ueberhorst, H. (eds.) The Modern Olympics. West Point: Leisure Press, 1976, pp. 109-169.

. 'Towards a Philosofical Anthropology of the Olympic Athlete and/as the Achieving Being'. In: INTERNATIONAL OLYMPIC ACADEMY. International Session of the International Olympic Academy, 22., The Moral Profile of Olympic Athlete. Report... Ancient Olympia: International Olympic Academy, 1982. p. 163-177.

LOLAND, Sigmund. 'Fair play: historical 
anachronism or topical ideal?' In: McNamee M.J. e Parry, S.J. (eds.) Ethics \&c Sport. London / New York: E \& FN Spon, 1998, pp. 69-103.

LOVISOLO, Hugo. A Arte da Mediação. Rio de Janeiro: Sprint, 1995.

MacALOON, John. 'Olympic Games and the Theory of Spectacle in Modern Society'. In: MacAloon J. (ed.), Rife, Drama, Festival, Spectacle. Rehearsals Toward a Theory of Cultural Performance. Philadelphia: Institute for the Study of Human Issues Press, 1984, p. 241280.

McDONALD, Deborah P. 'A Conceptual Analysis of Fair Play Within Olympism'. In: POST GRADUATE SEMINAR IN OLYMPIC STUDIES, 5., 1997, Ancient Olympia. Notes. Ancient Olympia, Greece: International Olympic Academy.

NETHERLANDS SPORT, TOLERANCE AND FAIR PLAY FOUNDATION. Tolerance and Fair Play General - Quiz. [s.1.], [s.n], 1997.

PARRY Jim. Drugs in sport - Some moral issues. Ancient Olympia: International Olympic Academy, 1997, (mimeo).

PNUD. Relatório do Desenvolvimento Humano 2000. Lisboa: PNUD/Trinova Editora. Disponível em: http://www.undp.org.br [capturado em 9 jul. 2000].

PORTELA, Fernando. Fair play, que Fair play?! Doutrina, ou Exercício da Moral? 1999. 117 p. Dissertação (Mestrado em educação física) - Programa de Pós Graduação em Educação Física da Universidade Gama Filho.

SANTOS, A. R. R. \& ROAZZI, A. Espírito Esportivo entre Universitários de Educação Física e Psicologia da cidade do Recife, Pernambuco, Brasil. In: CONGRESSO DE EDUCAÇÃO FISICA E CIÊNCIAS DO DESPORTO DOS PAISES DE LÍNGUA PORTUGUESA, 4., 1995, Coimbra. Anais... Coimbra: Portugal.

TAVARES, Otávio. Mens Fervida in Corpore Lacertoso? As atitudes dos atletas olímpicos brasileiros diante do Olimpismo. 1998. 132 p. Dissertação (Mestrado em educação física) - Programa de Pós Graduação em Educação Física da Universidade Gama Filho.

'Algumas reflexões para uma rediscussão do Fair Play'. In: Tavares, O., DaCosta, L.P. (eds.) Estudos Olímpicos. Rio de Janeiro: Editora Gama Filho, 1999, pp. 173-193.

. 'Referenciais teóricos para

o conceito de Olimpismo'. In: Tavares, O. e DaCosta, L.P. (eds.) Estudos Olímpicos. Rio de Janeiro: Editora Gama Filho, 1999, pp. 1549.

WADA-AMA. World Conference on Doping in Sport - Final Declaration. Lausanne, 4 de fevereiro de 1999. Disponível em www.wadaama.org. [capturado em 12 de março de 2001].

WEILER, Ingomar. 'Notes on Ancient Olympic Games'. In: POST GRADUATE SEMINAR IN OLYMPIC STUDIES, 5., 1997, Ancient Olympia. Notes. Ancient Olympia, Greece: International Olympic Academy.

Endereço do autor: Departamento de Ginástica/CEFD/UFES; Av. Fernando Ferrari, s/n; 29.060-970; Vitória, ES e-mail: otavares@uol.com.br

\section{Notas}

1 Mestre em educação física. Doutorando em educação física no Programa de Pós Graduação em Educação Física da Universidade Gama Filho. Professor Assistente do Departamento de Ginástica do Centro de Educação Física e Desportos da Universidade Federal do Espírito Santo.

2 Se a sociologia figuracional de Norbert Elias nos mostrou que valores sociais e valores de 
prática esportiva guardam entre si uma relação complexa de formação de significados, filósofos como Gunther Gebauer e Hans Lenk enfatizam a "perspectiva interna do praticante em definir o jogo" como uma dimensão essencial para a compreensão da moral do esporte. Cf. Gebauer (1992) e Lenk (1982).

3 Segundo Eduardo DeRose (1995), o registro mais antigo do uso de agentes dopantes é uma pintura do imperador chinês Shen-Nung, datada de 2700 a.C., que o mostra segurando folhas de uma erva (machuang), usualmente utilizada para preparar estimulantes. Do mesmo modo, segundo Weiler (1997), nos Jogos Olímpicos da Antigüidade muitos atletas acreditavam que a ingestão de certos chás de ervas e cogumelos poderiam melhorar seu desempenho durante as competições.

4 Esto relação tem se tornado de tal forma evidente que Secretaria Nacional Anti-Drogas, órgão do governo federal encarregado da coordenação do combate às drogas ilegais, lançou no ano 2000 um panfleto 'educativo' de combate ao doping esportivo. Baseado na mesma relação é que a maconha e a cocaína estão atualmente entre as drogas proibidas pelo Comitê Olímpico Internacional embora não haja consenso sobre seus efeitos sobre o desempenho esportivo.

$5 \mathrm{Um}$ exame exaustivo do Olimpismo como um construto é por mim apresentado em Tavares (1998).

6 A respeito do Olimpismo como uma construção eclética em busca da promoção de um equilíbrio entre contrários observe-se DaCosta (1999).

7 Há relatos até mesmo do uso de pequenas doses de nitroglicerina por parte de alguns atletas!

8 A mais recente destas organizações (1999) e, provavelmente, a mais poderosa delas todas é a WADA (World Anti Doping Association). Organizada como uma organização nãogovernamental, a WADA é uma instituição multilateral que congrega organizações esportivas, organizações governamentais e nãogovernamentais e órgãos internacionais. Tem estreita ligação com o Comitê Olímpico Internacional (COI), embora seja formal- mente independente, tendo tido suas ações iniciais financiadas por uma dotação de verba do COI da ordem de 25 milhões de dólares.

9 Segundo Lalande (1993:93), para Leibniz, assilogismo é um argumento cujas conseqüências lógicas válidas não podem ser postas sob a forma de um silogismo regular. Ou seja, os raciocínios assilogísticos, ao contrário dos silogismos, não são demonstráveis com rigor. Assim, em vez de extraírem conclusões não-evidentes a partir das evidências, os raciocínios assilogísticos possuem uma conclusão evidente e são a base de todos os outros raciocínios que possam ser reduzidos a eles.

10 Os estudos sobre o fair play realizados por Santos \& Roazzi (1995) e pelo Netherlands Sport, Tolerance and Fair Play Foundation (1997), são exemplos deste tipo de abordagem.

11 Estudos empíricos como os de Heinilä e Nilsson (apud Loland, 1998) na Europa e de Gomes (1999) e Portela (1999) no Brasil demonstram como as interpretações do conceito de fair play e suas ações conseqüentes podem variar segundo os mais diversos contrastes e razões.

12 A questão da articulação de valores éticos, técnicos e estéticos na prática esportiva é melhor desenvolvida por Hugo Lovisolo no capítulo 3, 'Regras, esportes, capitalismo: obrigatoriedade e escolha na educação física escolar' de $A$ Arte da Mediação (1995).

13 Em razão dos limites deste texto está se excluindo aqui a discussão sobre distinção necessária entre as violações intencionais e não intencionais e suas conseqüências práticas para o jogo e o 'espírito do jogo'.

14 Esta distinção aqui apresentada deve ser entendida como uma simplificação de uma discussão bastante complexa e, até certo ponto, inconclusa sobre as relações entre estes tipos de regras assim como sobre a real existência de distinções que instituam estas tipologias.

15 Observe-se que se segundo Loland (op. cit.), as regras regulatórias podem ser de diferentes tipos e ter diferentes graus de influência sobre a prática do jogo. Deste modo, para ele, as 
regras auxiliares propostas por Meyer são apenas uma sub-divisão das regras regulatórias, com o que não concordamos.

16 A este respeito observe-se o posicionamento do American College of Sports Medicine apresentado por Hatfield (1987).

17 No caso brasileiro, a bem sucedida associação entre a indústria de bebidas e o esporte tem no jogo final da Copa do Mundo de Futebol de 1994 um caso exemplar. A cena dos jogadores brasileiros comemorando a vitória final elevando o dedo indicador, à imagem e semelhança da campanha de uma grande cervejaria nacional veiculada durante todo o ano da Copa do Mundo, pode ser catalogado como um dos mais bem sucedidas campanhas de cunho subliminar jamais vistas no Brasil.

18 Frase atribuída a Aparício Torelli, lendário comediante brasileiro que adotou o pseudônimo de Barão de Itararé.

19 Apenas a título de ilustração, Hatfield (op. cit.), por exemplo, ao analisar o potencial de aprimoramento do rendimento durante a competição, ou a melhora do tempo de recuperação durante o treinamento, de 42 substâncias tendo como referência a força, a resistência e a massa muscular demonstrou que, no primeiro caso, apenas 7 substâncias tem efeitos sobre a força, 9 substâncias tem efeitos sobre resistência e 6 tem efeitos sobre a massa muscular. Já no segundo caso, apenas 6 substâncias tem efeitos sobre a força, 7 sobre a resistência e 6 sobre a massa muscular. Em ambos os casos a grande maioria das substâncias foi classificada como não tendo efeitos ou sendo de efeito duvidoso.

20 Não coincidentemente aquelas bicicletas foram conhecidas como moonbikes (bicicletas lunares) em função da altíssima tecnologia envolvida em seu projeto e construção.

21 A ordem das opções de ação possíveis aqui apresentadas são meramente ilustrativas. Como Breivik (ibid.) já demonstrou, a determinação de sua ordenação vai depender, dentro da teoria dos jogos, de diferentes tipologias de jogo (simétricos; assimétricos; $2 \times 2 ; \mathrm{N}$ casos $\mathrm{x} \mathrm{N}$ casos) e das respectivas estratégias dominantes por parte dos atletas envolvidos.
22 Mas, ao contrário do caso anterior, pela situação exemplificada na teoria do jogos pelo 'dilema do prisioneiro'.

23 Este texto é, em parte, fruto de discussões que tive com o Prof. Dr. Jim Parry, chefe do Departamento de Filosofia da Universidade de Leeds (Inglaterra), sobre moral e esporte, durante o Postgraduate Seminar on Olympism de 1997 na International Olympic Academy (Olímpia Antiga, Grécia). A ele, meu reconhecimento.

Recebido em: 19.11 .01

Revisadoem:01.03.02

Aceitoem: 22.03 .02 
